\title{
Investigating the effect of job stress and emotional intelligence on job performance
}

\author{
Mojtaba Rafiee $^{\mathrm{a}}$, Hojat Kazemi ${ }^{\mathrm{b}^{*}}$ and Mustafa Alimiri ${ }^{\mathrm{c}}$
}

\section{H R O N I C L E}

\section{Article history:} \\ Received May 12, 2013 \\ Received in revised format \\ 12 August 2013 \\ Accepted 14 August 2013 \\ Available online \\ August 162013 \\ Keywords: \\ Job stress \\ Emotional intelligence \\ Organizational intelligence \\ Moral intelligence \\ Job performance \\ Structural equation modeling
}

${ }^{a}$ Assistant Professor, Pyam-Nour University, Arak branch, Arak, Iran

${ }^{b}$ M.A Student of Management, Islamic Azad University, Arak Branch, Iran

${ }^{c}$ Assistant Professor, Islamic Azad University, Arak branch, Arak, Iran

\begin{abstract}
A B S T R A C T
Researchers and scholars of management and behavioral sciences have tried to determine effective factors, which influence on efficiency and effectiveness in order to increase organization performance and they have tried to identify factors, which create job stress. In this research, we investigate the effect of job stress on job performance through emotional, organizational and moral intelligence. The study is a descriptive-analytic one, which is based on correlation, uses survey method to gather data and they are analyzed using structural equation modeling. The population of this research includes all the personnel of Registry Organization in Arak city. The results suggest that job stress influences on job performance through organizational intelligence and moral intelligence, but job stress does not influence on job performance through emotional intelligence. Regarding research hypotheses, results and findings after analyzing obtained data suggest that job stress influences on emotional, organizational and moral intelligence, but job stress does not influence on job performance. In addition, the results show that organizational and moral intelligence influence on job performance but emotional intelligence does not influence on job performance.
\end{abstract}

\section{Introduction}

During the past few years, there have been tremendous changes on economy and there is a growing competition among business owners, which means they need to have more skilled employees. There is no doubt that these people are required to act more efficiently and effectively (Albrekht, 2003). The results of recent studies show that existence of such characteristics and capabilities among employees require a kind of superior intelligence, which is beyond individual cognitive and conceptual

\footnotetext{
*Corresponding author.

E-mail address: mazm1985@gmail.com (H. Kazemi) 
intelligence. Emotional intelligence is the most recent revolution in understanding the relationship between thought and emotion. This term was first suggested by Mayer and Salovey (1995) as "emotional intelligence is the ability of person to perceive, express, identify and handle his own and others emotions". Since the main components of emotional intelligence in individual are the ability to realize others emotions and the ability to control him/herself and others consistently, it is expected that those who have high emotional intelligence, represent social compatibility and better social skills. This claim that intelligence leads to job performance, has been repeated in recent articles in which management researchers explain that: "intelligence is the best predictor of job performance". Psychology-industry literature has agreed on explaining the relationship between strong IQ and job performance, meaning that those who are clever transform their knowledge associated with their jobs better and faster. Especially, researchers claim that personnel emotional intelligence can predict the results associated with work including job satisfaction and job performance. Schmidt and Hunter stated that intelligence is the main determining factor in job performance. Therefore, employing people based on intelligence leads to improvement in job performance (Byington \& Felps, 2010). Recently, several studies have been accomplished about the indirect effects of job stress model on job performance based on different samples. The results of different surveys show that the ability of employees to use their emotions and feelings and also the ability of them to influence on feelings of other personnel directly decrease physical and psychological stress in work situation. These findings are consistent with obtained theories associated with emotions and feelings.

Some researchers reasoned that job performance under the effect of employee capability for applying emotions is applied to facilitate their emotions. Personnel can use positive and negative aspects of their feelings to improve their performance. As an example, positive feeling like emotions and excitement can stimulate employees to provide better service to customers, fulfil job duties or cooperate in organization. In contrast, negative feelings like stress can facilitate personnel ability to concentrate on their job duties. In spite of some limited studies in this field, several studies have emphasized the cognitive aspects of personnel performance and have less focused on the effects of emotional dimensions.

\section{Literature review}

\subsection{Performance}

Job performance can be specified as employees' ability to carry out their duties, responsibilities and tasks. Job performance is a human behavior considered as an important factor to assess the effectiveness of individual work in organization. This approach states that success or failure of organization depends on individuals' job performance within organization. Employee job performance is an important factor to put organization on pressure to be the best one. According to Phillips (1998), job performance is defined as "the extent that personnel behaviors improve organization effectiveness". Personnel effectiveness is reported as their performance in work situation. Job performance is individual productivity in quantitative and qualitative aspects of job. The performance shows how an individual do his/her work well and considers the job satisfaction from job duties, policies and organization standards. The job performance, which is depended on work situation, is a set of job and social interactions. For an organization to reach its own goals, employees should do their works in an accepted level of effectiveness. This is a critical and necessary factor for state organizations whose weak performance provides the failure in carrying out public services, and it is necessary for private companies whose weak performance causes their bankruptcy. From a social viewpoint, the most interesting issue for organizations is having employees who do their works well. Good performance increases organization productivity, which finally leads to an increase in national economy (Spector, 1986). Generally, the main objective of every performance measurement system is to encourage managers and employees to perform organization strategies successfully. Those organizations that can translate their strategies to performance measurement system can do better in carrying out their own strategies, because they have transmitted their goals to 
all personnel of the organization. In fact, performance measurement and evaluation lead to system intelligence and individual motivation to ideal behavior. It is an important part of codifying and performing organization policy (Turner et al., 2002).

\subsection{Job stress}

When we consider that, at least, people spend one third of their lives in work situation and most of people's social relationships are formed during work times, we realize that the resulted stress from work or job, in addition to effectiveness can influence on people's health and satisfaction, significantly. Generally, those who have more stress will have less job satisfaction and will be less healthy. Stress exists in the life of all people who work in different jobs and it puts them under pressure in various ways. Job evolutions like organization changes, wage and salary changes, job promotions or human force reduction or increase and social changes are issues, which put individual on pressure and make him or her confused or worried (Knight et al., 2007). In organization, context occupational stress is known as job stress or work stress. These terms are used in place of each other, but in fact, they refer to one issue. Stress manifests itself in many ways. An individual, who tolerates more stress, may experience blood pressure, stomach sores, irritability, and may have problems in making simple and repetitive decisions and may lose his enthusiasm.

\subsection{Organizational intelligence}

The concept of organization intelligence first was raised by Harold Wilensky in 1967. He believed that the collected data of intelligence are shown and processed to determine correct organization. Alberkht (2003) considered the success of an organization as having smart people, smart teams and smart organizations. Alberkht used organization intelligence to provide responsiveness and to prevent group stupidity and presented a model for organization intelligence, which includes seven dimensions including strategic vision, shared fate, appetite for change, alignment and conference, spirit, knowledge deployment and sperformance pressure. Organization intelligence creates the total capacity of organization by using available information through collecting data, analyzing them, producing knowledge and learning new decisions in organization.

\subsection{Emotional intelligence}

The first theories of emotional intelligence state that factors other than logical intelligence can increase effectiveness (Cherniss, 2001, 316). Psychologists have identified various kinds of intelligence and have classified them in three main groups:

Abstract intelligence: The ability to perceive and apply mathematical and speech symbols skillfully, Spiritual intelligence: The ability to perceive and meet problems skillfully (Rezaei, 2012), Social intelligence: The ability to perceive and communicate with people (Johnson \& Indvik, 1999).

Theorists have presented various definitions for emotional intelligence from the early times of its development. Mayer and Salovey (1995) defined emotional intelligence as the ability of individual to evaluate, express and manage his/her emotions. Mayer et al. (2004) defined emotional intelligence as the ability of individual to manage his/her emotions and that of others, identify and differentiate between them and use obtained data to guide and direct his/her thoughts and actions (Chiva \& Alegre, 2007, 680). In fact, emotional intelligence has presented new depths to human intelligence and has expanded it to the ability of evaluating individual's common intelligence. New studies indicated that unlike most philosophers and psychologists beliefs, cognition and emotion are not independent from each other, but instead there are many relations and correlations between thoughts and feelings in humans' social life. On the other hand, our feelings and behaviors can have a fundamental impact on our mental life, actions and behaviors. However, until recently we did not know completely about these effects. 


\subsection{The relationship between job stress, emotional intelligence and job performance}

Many believe that emotional intelligence is the main concern of firms and organizations and its importance has increased beyond cognitive capacities and technical knowledge. The reason is that mangers realized that they could increase internal cooperation and individual-organization balance through emotional intelligence. As we know, organizations are different sets of groups, and successful interactions of groups to help organization flexibility, conformity and variation. Therefore, organizations use soft skills, which are based on emotions, to increase their effectiveness. Recent studies have shown that mangers with high emotional intelligence produce positive work related views and gregarious behaviors and employees can enjoy high job performance and satisfaction. Mangers with high emotional intelligence can facilitate personnel performance through managing their emotions in order to strengthen their creativity, flexibility and trust. Mayer et al. (2004) stated that emotional intelligence influences on work and job performance and within individuals interactions (LeDoux, 2003).

\subsection{Moral Intelligence}

Moral intelligence means concentrating on nature and human life, economic welfare, true and free communications and citizenship rights. In today's world, just managers with high moral intelligence can generate commitment and trust in organizations, which are a basis for a wide and true business. The experiences of business mangers indicated that moral behavior is not just to do work, correctly, but it is to do a correct work.

\section{The proposed model}

The hypotheses of current research are as the following:

1. Job stress influences on job performance through emotional intelligence.

2. Job stress influences on job performance through organization intelligence.

3. Job stress influences on job performance through moral intelligence.

The especial hypotheses of current research are presented here and they are shown in Fig. 1.

1. Job stress influences on job performance.

2. Job stress influences on emotional intelligence.

3. Emotional intelligence influences on job performance.

4. Job stress influences on organization intelligence.

5. Organization intelligence influences on job performance.

6. Job stress influences on moral intelligence.

7. Moral intelligence influences on job performance

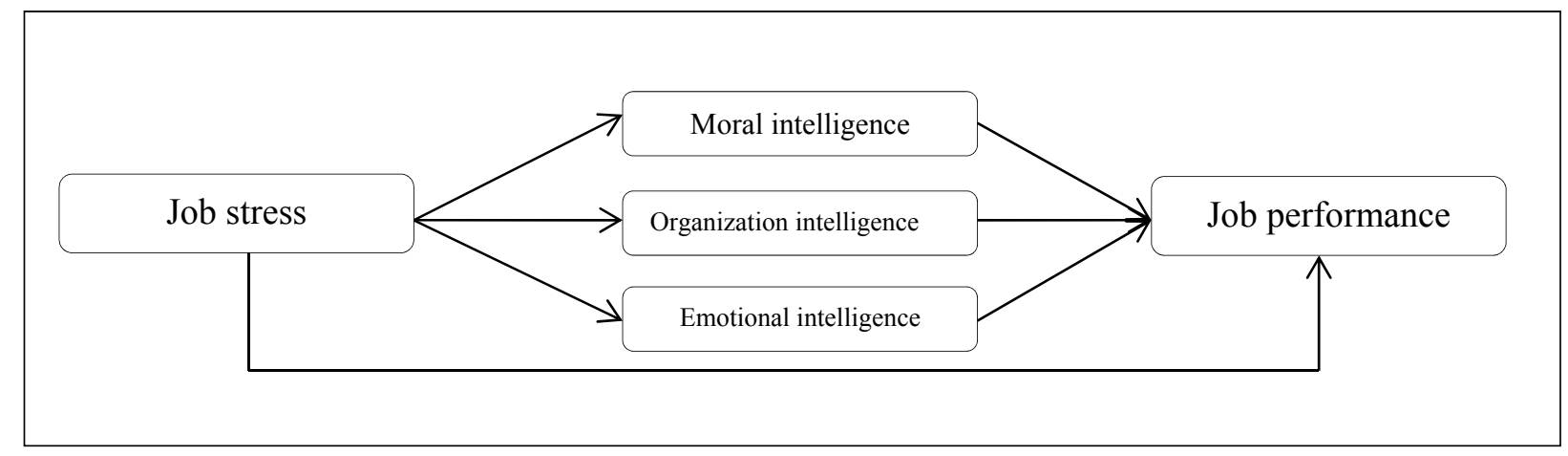

Fig. 1. The proposed study 


\subsection{Research methodology}

This research is descriptive-analytic. The statistical population of this research includes all 150 employees of Registry Office in Arak city. Questionnaires were distributed among all of them and we managed to collect 130 valid and useable ones. To collect data, library and field studies were used. The instruments of gathering data were observation, interview and standard questionnaires. Research questionnaires were adjusted in three parts: The first part was the request for completing questionnaire. In the second part, some demographic information of respondents was raised and the third part included 45 questions, which were designed by five-points of Likert scale. According to research goals, questions were divided in terms of completely agree through completely disagree. In this research, the views of some expert professors in marketing field were used to investigate questionnaire validity. In addition, the content validity was supported. To determine reliability, Alpha Cranach was used. Alpha coefficient for the questionnaire in pre-test (3o questionnaires) was 0.903 and for each question in pre-test and post-test was more than 0.7 , which validates the survey.

\section{The results}

To investigate the meaningfulness between indexes and factors, confirmatory factor analysis was conducted and the results are shown in Tables 1-3.

\section{Table 1}

Measurement model results of external variables

\begin{tabular}{|c|c|c|c|c|}
\hline Research construct & Symbol in model & Factor load & $\mathrm{t}$ & $\mathrm{p}$-value \\
\hline \multirow[t]{10}{*}{ Moral intelligence } & $\mathrm{Y}_{1}$ & 0.42 & 5.08 & One percent \\
\hline & $\mathrm{Y}_{2}$ & 0.48 & 5.97 & One percent \\
\hline & $\mathrm{Y}_{3}$ & 0.35 & 4.19 & One percent \\
\hline & $\mathrm{Y}_{4}$ & 0.63 & 8.32 & One percent \\
\hline & $\mathrm{Y}_{5}$ & 0.65 & 8.63 & One percent \\
\hline & $\mathrm{Y}_{6}$ & 0.41 & 5.04 & One percent \\
\hline & $\mathrm{Y}_{7}$ & 0.76 & 10.61 & One percent \\
\hline & $\mathrm{Y}_{8}$ & 0.83 & 12.16 & One percent \\
\hline & $\mathrm{Y}_{9}$ & 0.50 & 6.28 & One percent \\
\hline & $\mathrm{Y}_{10}$ & 0.16 & 1.91 & One percent \\
\hline \multirow[t]{10}{*}{ Emotional intelligence } & $\mathrm{Y}_{11}$ & 0.59 & 7.15 & One percent \\
\hline & $\mathrm{Y}_{12}$ & 0.64 & 7.80 & One percent \\
\hline & $\mathrm{Y}_{13}$ & 0.37 & 4.12 & One percent \\
\hline & $\mathrm{Y}_{14}$ & 0.38 & 4.29 & One percent \\
\hline & $\mathrm{Y}_{15}$ & 0.51 & 6.01 & One percent \\
\hline & $\mathrm{Y}_{16}$ & 0.32 & 3.59 & One percent \\
\hline & $\mathrm{Y}_{17}$ & 0.05 & 0.50 & One percent \\
\hline & $\mathrm{Y}_{18}$ & 0.24 & 2.68 & One percent \\
\hline & $\mathrm{Y}_{19}$ & 0.55 & 6.59 & One percent \\
\hline & $\mathrm{Y}_{20}$ & 0.25 & 2.83 & One percent \\
\hline \multirow[t]{8}{*}{ Job performance } & $\mathrm{Y}_{21}$ & 0.52 & 6.53 & One percent \\
\hline & $\mathrm{Y}_{22}$ & 0.70 & 9.56 & One percent \\
\hline & $\mathrm{Y}_{23}$ & 0.77 & 10.85 & One percent \\
\hline & $\mathrm{Y}_{24}$ & 0.60 & 7.84 & One percent \\
\hline & $\mathrm{Y}_{25}$ & 0.67 & 8.97 & One percent \\
\hline & $\mathrm{Y}_{26}$ & 0.18 & 2.17 & One percent \\
\hline & $\mathrm{Y}_{27}$ & 0.75 & 10.41 & One percent \\
\hline & $\mathrm{Y}_{28}$ & 0.74 & 10.35 & One percent \\
\hline \multirow[t]{6}{*}{ Job stress } & $\mathrm{Y}_{29}$ & 0.61 & 8.46 & One percent \\
\hline & $\mathrm{Y}_{30}$ & 0.28 & 4.09 & One percent \\
\hline & $\mathrm{Y}_{31}$ & 0.75 & 10.79 & One percent \\
\hline & $\mathrm{Y}_{32}$ & 0.34 & 4.78 & One percent \\
\hline & $\mathrm{Y}_{33}$ & 0.23 & 3.23 & One percent \\
\hline & $\mathrm{Y}_{34}$ & 0.47 & 6.54 & One percent \\
\hline \multirow[t]{11}{*}{ Organization intelligence } & $\mathrm{Y}_{35}$ & 0.82 & 11.78 & One percent \\
\hline & $\mathrm{Y}_{36}$ & 0.67 & 8.93 & One percent \\
\hline & $\mathrm{Y}_{37}$ & 0.87 & 13.09 & One percent \\
\hline & $\mathrm{Y}_{38}$ & 0.49 & 6.16 & One percent \\
\hline & $\mathrm{Y}_{39}$ & 0.25 & 3.02 & One percent \\
\hline & $\mathrm{Y}_{40}$ & 0.15 & 1.77 & One percent \\
\hline & $\mathrm{Y}_{41}$ & 0.55 & 6.78 & One percent \\
\hline & $\mathrm{Y}_{42}$ & 0.09 & 1.09 & One percent \\
\hline & $\mathrm{Y}_{43}$ & 0.18 & 2.16 & One percent \\
\hline & $\mathrm{Y}_{44}$ & 0.61 & 7.91 & One percent \\
\hline & $\mathrm{Y}_{45}$ & 0.32 & 3.84 & One percent \\
\hline
\end{tabular}


For meaningfulness of each parameter in the model, t-statistics was used. This statistics is obtained by the ratio of each parameter coefficient to the standard error of each parameter. The absolute value of $t$ should be greater than 2 , in order to these estimations be significant, statistically. The results of confirmatory factor analysis are shown in Table 1 . According to this table, the value of $t$ statistics in four constructs of research has been less than 2 (the questions 10, 17, 40 and 42).

In general, according to the test, the value of Chi-square was obtained 1555.82, to determine the accuracy of structural equation model while degree of freedom was 939 and significance level was $\mathrm{P}=0.000$. It shows that structural equation model has good fitness and it can determine final internal latent variable i.e. brand critical value. Also the value of RMSEA was 0.066, which is less than 0.1, and it can be claimed that structural model has the required fitness and validity and follows a causal structural model.

In addition, the accuracy of GFI and AGFI models were obtained 0.9 and 0.84 , respectively, which shows the accuracy of Gama, Beta and Landau coefficients and it can be generalized to the whole of population. Also it shows that the presented structural model has the least external error of model.

\section{Table 2}

The coefficients of constructs effects path and significance of estimated parameters

\begin{tabular}{lccc}
\hline The studding path in model & Path coefficients & t-value & test result \\
\hline Moral intelligence $\rightarrow$ job performance & 0.46 & 2.72 & Supported \\
Emotional intelligence $\rightarrow$ job performance & 0.23 & 1.83 & Rejected \\
Organization intelligence $\rightarrow$ job performance & 0.31 & 3.07 & Supported \\
Job stress $\rightarrow$ Moral intelligence & 0.99 & 5.19 & Supported \\
Job stress $\rightarrow$ Emotional intelligence & 0.77 & 6.14 & Supported \\
Job stress $\rightarrow$ Organization intelligence & 0.75 & 8.37 & Supported \\
\hline
\end{tabular}

Accoding to Table 2, which shows a summary of hyotheses results, moral intelligence influences on job performance with sinificance level of 2.72, organization intelligence influences on job performance with significance level of 3.07, job stress influences on moral intelligence with significance level of 5.19, job stress on emotional intelligence with significance level of 6.14 and job stress influences on organization intelligence with significance level of 8.37.

All of the hypotheses are supported, except the effect of emotional intelligence on job performance with significance level of 1.83, which is less than 1.96, thus this hypothesis is not supported.

\section{Table 5}

Fitness indexes of structural model

\begin{tabular}{lcc}
\hline index & & Reported value \\
\hline Root Median of Reminders (RMR) & Near to zero & 0.17 \\
Standardized Root Median of Reminders SRMR & Near to zero & 0.1 \\
Goodness of Fit Index (GFI) & 0.9 and higher & 0.90 \\
Neutralized Fit Index (NFI) & 0.9 and higher & 0.92 \\
Not Neutralized Fit Index (NNFI) & 0.9 and higher & 0.92 \\
Increment Fit Index (IFI) & 0.9 and higher & 0.92 \\
Comparative Fit Index (CFI) & & 0.92 \\
Root Median of Standard Error access RMSEA & Less than 0.8 & 0.066 \\
\hline
\end{tabular}




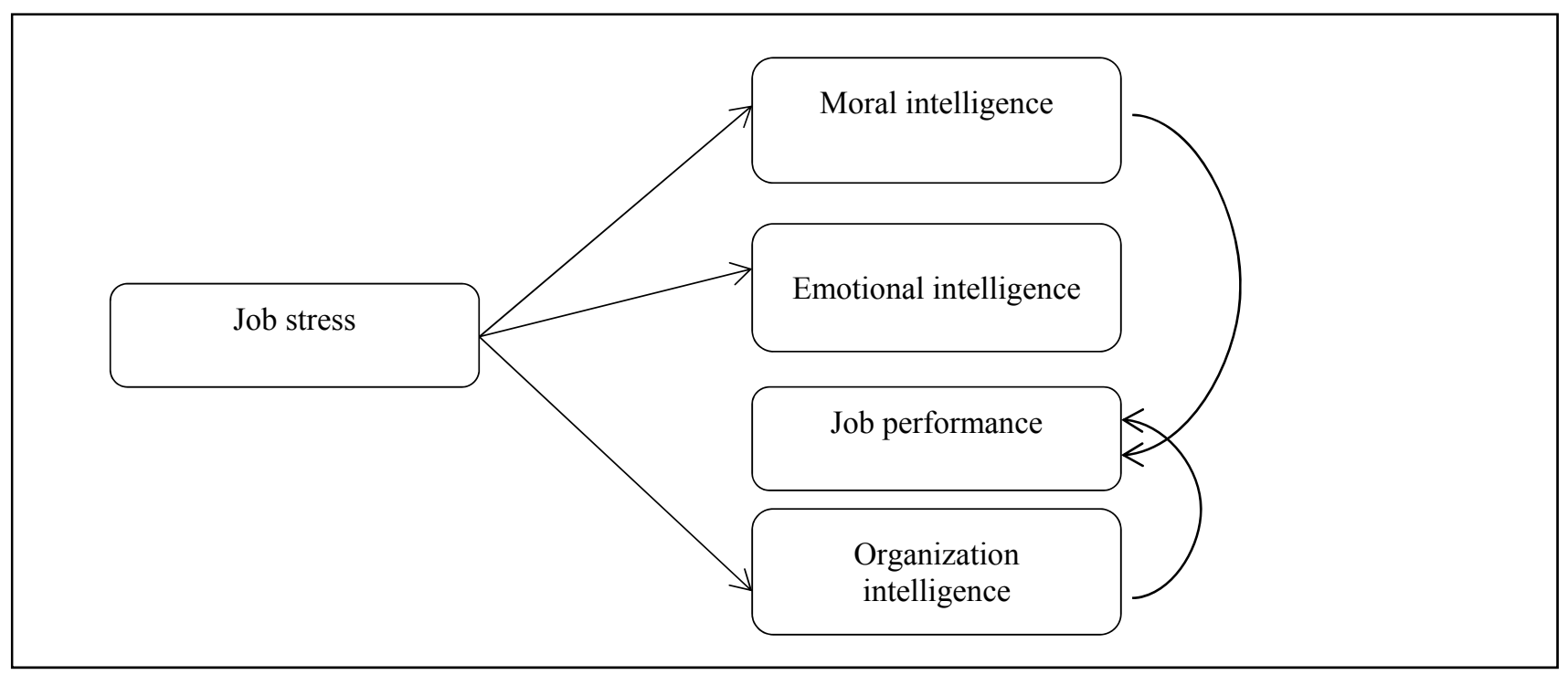

Fig. 2. The results of the survey

\section{Conclusion}

The purpose of this study was to investigate the effect of job stress on job performance by meditative effects of emotional intelligence, moral intelligence and organization intelligence. According to the results, job stress had direct effect on emotional intelligence, moral intelligence and organization intelligence and had indirect effect on job performance through moral and organization intelligence. Thus, following suggestions are presented:

1. The results of testing the second hypothesis have shown the effect of job stress on emotional intelligence. Therefore, it is suggested that a curriculum to be arranged by Arak city Registry organization, in order to strengthen emotional intelligence and some workshops to be held by them, in order to make organization personnel more compatible with stressful conditions.

2. Increasing self-consciousness and identifying organization members weak and strong points cause individuals realize their own knowledge, skills and abilities and adapt themselves with their job requirements. As a result, job stress decreases.

3.Incorporating individual goals with organization goals cause the individual to be more eager to meet his/her own job expectations, which, in turn, leads to the improvement of employee performance and satisfaction of their needs in organization.

4. The results of testing the sixth hypothesis shows the effect of job stress on moral intelligence. Therefore, it is suggested that Registry Organization considers the following issues in order to decrease job stress of personnel:

- developing missions, human values and ideals and creating value starts in organization,

- creating trust, confidence and responsiveness among organization members,

- adopting promotion decisions fairly and reward and motivation system among organization members,

- updating good moral values in organization. 
5. According to the research findings, organization intelligence and moral intelligence effect on job performance. Therefore, it can be stated that intelligence is the main determinant factor in job performance. Thus it is suggested that Registry Organization should pay attention to intelligence when employing and providing human forces.

\section{Acknowledgment}

The authors would like to thank the anonymous referees for their construction comments on earlier version of this work.

\section{References}

Albrekht, K. (2003). The Power of Minds at Work: Organizational Intelligence in Action. American Management Association.

Byington, E., \& Felps, W. (2010). Why do IQ scores predict job performance?: An alternative, sociological explanation. Research in Organizational Behavior,30, 175-202.

Cherniss, C. (2001). Emotional intelligence and organizational effectiveness. The emotionally intelligent workplace: How to select for, measure, and improve emotional intelligence in individuals, groups, and organizations, 3-12.

Chiva, R., \& Alegre, J. (2008). Emotional intelligence and job satisfaction: the role of organizational learning capability. Personnel review, 37(6), 680-701.

Johnson, P. R., \& Indvik, J. (1999). Organizational benefits of having emotionally intelligent managers and employees. Journal of workplace learning,11(3), 84-88.

Knight, D. K., Kim, H. J., \& Crutsinger, C. (2007). Examining the effects of role stress on customer orientation and job performance of retail salespeople. International Journal of Retail \& Distribution Management, 35(5), 381-392.

LeDoux, J. E. (2003). Synaptic self: How our brains become who we are. Penguin. com.

Mayer, J. D., \& Salovey, P. (1995). Emotional intelligence and the construction and regulation of feelings. Applied and preventive psychology, 4(3), 197-208.

Mayer, J. D., Salovey, P., \& Caruso, D. R. (2004). Emotional intelligence: Theory, findings, and implications. Psychological Inquiry, 15(3), 197-215.

Phillips, J. M. (1998). Effects of realistic job previews on multiple organizational outcomes: A metaanalysis. Academy of Management Journal, 41(6), 673-690.

Rezaei, H. (2012). The application of information technology and its relationship with organizational intelligence. Procedia Technology, 1, 94-97.

Spector, P. E. (1986). Perceived control by employees: A meta-analysis of studies concerning autonomy and participation at work. Human relations,39(11), 1005-1016.

Turner, N., Barling, J., Epitropaki, O., Butcher, V., \& Milner, C. (2002). Transformational leadership and moral reasoning. Journal of applied Psychology, 87(2), 304. 